Correction

\title{
Correction: Jain, S., et al. The Influence of Absolute Mass Loading of Secondary Organic Aerosols on Their Phase State. Atmosphere, 2018, 9, 131
}

\author{
Shashank Jain, Kevin B. Fischer and Giuseppe A. Petrucci * \\ Department of Chemistry, University of Vermont, 82 University Place, Burlington, VT 05405, USA; \\ shashank.jain@agilent.com (S.J.); Kevin.Fischer@uvm.edu (K.B.F.) \\ * Correspondence: Giuseppe.petrucci@uvm.edu; Tel.: +1-802-656-0957
}

Received: 12 October 2019; Accepted: 15 October 2019; Published: 18 October 2019

The authors would like to correct the published article [1] concerning the acknowledgments, as follows: This material is based upon work supported by the National Science Foundation under Grant No. CHE-1709751.

\section{Reference}

1. Jain, S.; Fischer, K.B.; Petrucci, G.A. The Influence of Absolute Mass Loading of Secondary Organic Aerosols on Their Phase State. Atmosphere 2018, 9, 131. [CrossRef]

(C) 2019 by the authors. Licensee MDPI, Basel, Switzerland. This article is an open access article distributed under the terms and conditions of the Creative Commons Attribution (CC BY) license (http://creativecommons.org/licenses/by/4.0/). 